\title{
CORRESPONDENCE
}

\section{PROPOSED GUIDELINES FOR CLENBUTEROL FOOD POISONING}

\section{To the Editor:}

Administering growth-promoting medicines to animals that are intended for human consumption is an illegal practice in the European Union because the ingestion of food containing residues of such chemicals is a risk to public health. Clenbuterol is the $\beta_{2}$-adrenergic agonist most frequently used illegally to promote growth in animals, and the intoxications it has produced to date should therefore surprise no one (1-3). We report on 50 intoxicated patients in four cases in Portugal (Table).

In Ourém, in 10 patients between 5 and 60 years of age, symptoms appeared shortly after ingestion of lamb meat, although the first patients were not admitted to the health unit until 7 to 8 hours after the meal. No complementary diagnostic tests were made, and diazepam taken orally was used for therapy.

In Lousã, 2 affected patients 58 and 28 years of age were admitted to the hospital 2 hours after ingestion of bovine liver. Complementary laboratory tests were made and in both cases showed leucocytosis with neutrophilia, hyperglycemia, and hypokalemia. Therapy consisted of diazepam taken intramuscularly, propranolol taken orally, and potassium chloride diluted in physiologic salt solution taken intravenously.

In Ovar, 34 patients between 19 and 58 years of age showed signs of food poisoning 4 to 15 hours after ingesting bovine liver. Five of the patients had light hyperglycemia, and only 1 of the patients who had a leucogram showed leucocytosis with neutrophilia. A supporting therapy was chosen, with hydroelectrolytic solutions, paracetamol, lysine acetylsalicylate, loperamide, metochlopramide, and cotrimoxazol.

In Peso da Régua, 4 intoxicated people between 4 and 42 years of age
Table. Symptoms in 50 Patients with $\beta_{2}$ Adrenergic Agonist-Induced Food Poisoning.

\begin{tabular}{lc}
\hline \multicolumn{1}{c}{ Symptoms } & Frequency \\
\hline $\begin{array}{l}\text { Tachycardia }(>100 \\
\text { beats/min) }\end{array}$ & $82 \%$ \\
Distal tremors & $75 \%$ \\
Nausea & $74 \%$ \\
Epigastralgias & $68 \%$ \\
Diarrhea & $50 \%$ \\
Fever $\left(>37.5^{\circ} \mathrm{C}\right)$ & $36 \%$ \\
Headaches and dizziness & $36 \%$ \\
Myalgias and asthenia & $22 \%$ \\
Hypertension $(>150 / 80$ & $18 \%$ \\
$\quad$ mm Hg) & \\
Vomiting & $18 \%$ \\
Dry mouth and voice & $10 \%$ \\
changes & \\
\hline
\end{tabular}

presented with symptoms about 90 minutes after ingesting beef. No complementary diagnostic tests were made, and the therapy was limited to the administration of physiologic salt solution and metochlopramide, taken intravenously.

The diagnosis of food poisoning due to residues of a $\beta_{2}$-adrenergic agonist (most likely clenbuterol) was shown to be correct following an analysis of remaining samples of the food and the blood taken from 2 patients.

We propose a guideline to assist in cases of food poisoning due to a $\beta_{2}$-adrenergic agonist. A collection of urine and blood from the patients, as well as of any food that may be left from the meal, must be compulsory, to be followed by the preservation of the samples at $-20^{\circ} \mathrm{C}$ for later analysis in a specialized laboratory. An additional blood analysis for hemogram, glycemia, and kalemia and an electrocardiogram are also suggested auxiliary means of diagnosis. Therapy with a beta-blocker and intravenous potassium chloride is also recommended to correct hypokalemia, which may cause serious arrhythmias, particularly in patients who take digoxin or other cardiotonics.
However, because the intoxication may persist for up to 5 days, it may be necessary to extend the treatment.

Because of the high toxicity of clenbuterol residues in food, we also suggest that patients be closely watched, particularly if they suffer from ischemic cardiopathies, high blood pressure, or associated hydroelectrolytic problems; if they need diuretics; or if they are being treated with medicines from the same therapeutic group.

Fernando Ramos, PhD Irene Silveira, $P h D$

Faculdade de Farmácia Universidade de Coimbra Coimbra, Portugal

José M. Silva, PhD Faculdade de Medicina Universidade de Coimbra Coimbra, Portugal

Jorge Barbosa, PharmD Clara Cruz, MD

Laboratório Nacional de Investigação Veterinária Lisboa, Portugal

José Martins, MD Serviço de Saúde Pública Ourém, Portugal

Celeste Neves, MD Centro de Saúde de Ovar Ovar, Portugal

Carlos Alves, $M D$

Delegação de Saúde de Peso da Régua Peso da Régua, Portugal

1. Martinez-Navarro JF. Food poisoning related to consumption of illicit beta-agonist in liver. Lancet. 1990;336:1311.

2. Brambilla G, Loizzo A, Fontana L, et al. Food poisoning following consumption of clenbuterol-treated veal in Italy. J Am Med Assoc. 1997;278:635.

3. Brambilla G, Cenci T, Franconi F, et al. Clinical and pharmacological profile in a clembuterol epidemic poisoning of contaminated beef meat in Italy. Toxicol Lett. 2000;114:47-53. 